L. Duvillard · E. Florentin · M. L. Lalanne-Mistrich •

J. M. Petit · S. Baillot-Rudoni · A. Brun-Pacaud ·

J. M. Brun · P. Gambert · B. Vergès

\title{
Normal metabolism of apolipoprotein B100-containing lipoproteins despite qualitative abnormalities in type 1 diabetic men
}

Received: 10 December 2004 / Accepted: 7 February 2005 / Published online: 26 May 2005

C) Springer-Verlag 2005

\begin{abstract}
Aims/hypothesis: Type 1 diabetic subjects are at increased risk of cardiovascular disease and exhibit multiple qualitative abnormalities of apolipoprotein (apo) B100-containing lipoproteins. This stable isotope kinetic experiment was designed to study whether these abnormalities are associated with changes in the synthesis and fractional catabolic rates of VLDL-, IDL- and LDLapoB100. Methods: Using a bolus followed by a 16-h constant infusion of ${ }^{13} \mathrm{C}$-leucine, we performed a kinetic study in eight men with type 1 diabetes treated with a continuous subcutaneous insulin infusion administered by an external pump and in seven healthy men, in the fed state. Results: The mean $\mathrm{HbA}_{1} \mathrm{c}$ level in the type 1 diabetic patients was $8.00 \pm 1.48 \%$. Plasma triglyceride, and total, LDL and HDL cholesterol levels were similar in patients and control subjects. VLDL were less triglyceride rich in type 1 diabetic patients than in control subjects (VLDL triglyceride : apoB $6.91 \pm 0.81 \mathrm{vs} 8.29 \pm 1.24 \mathrm{mmol} /$ $\mathrm{g}, p=0.05)$. Conversely, the IDL and LDL of the type 1 diabetic patients contained relatively higher levels of triglycerides (IDL triglycerides : apoB $2.16 \pm 0.36$ vs $1.57 \pm$ $0.30 \mathrm{mmol} / \mathrm{g}, p<0.01$; LDL triglycerides : apoB $0.27 \pm 0.06$ vs $0.16 \pm 0.04 \mathrm{mmol} / \mathrm{g}, p<0.05$ ). The apoB100 pool size, production and fractional catabolic rates in the two groups of subjects were similar for all lipoprotein fractions. Conclusions/interpretation: Despite qualitative abnormalities, especially abnormalities of triglyceride content, the metabolism of apoB100-containing lipoproteins is not al-
\end{abstract}

\footnotetext{
L. Duvillard $(\bowtie) \cdot$ E. Florentin $\cdot$ J. M. Petit ·

P. Gambert $\cdot$ B. Vergès

INSERM U498, Bocage Hospital,

BP 77908, 21079 Dijon Cédex, France

e-mail: laurence.duvillard@chu-dijon.fr

Tel.: +33-380-293646

Fax: $+33-380-293661$

M. L. Lalanne-Mistrich · J. M. Petit · S. Baillot-Rudoni ·

A. Brun-Pacaud · J. M. Brun · B. Vergès

Department of Endocrinology and Metabolic Diseases,

Bocage Hospital,

Dijon, France
}

tered in type 1 diabetic men with fair glycaemic control with continuous subcutaneous insulin infusion. The high risk of atherosclerosis in these patients cannot be explained by kinetic abnormalities of apoB100-containing lipoproteins.

Keywords Apolipoprotein B100 - IDL - Kinetic study · LDL - Stable isotope - Type 1 diabetes mellitus - VLDL

Abbreviations apo: apolipoprotein FCR: fractional catabolic rate - LPL: lipoprotein lipase · MTP: microsomal triglyceride transfer protein

\section{Introduction}

Patients with type 1 diabetes mellitus have an increased risk of premature atherosclerosis. Quantitative plasma lipid abnormalities characterised by moderate hypertriglyceridaemia and hypercholesterolaemia have been reported in patients with poorly controlled type 1 diabetes $[1,2]$. Patients with good-to-fair glycaemic control have plasma triglyceride and cholesterol concentrations similar to those observed in healthy subjects; however, qualitative abnormalities have been observed in patients treated with subcutaneous insulin, despite normal plasma lipid levels. VLDL particles have been demonstrated to be rich in cholesterol and poor in triglycerides, resulting in an increased cholesteryl ester : triglyceride ratio in these particles [3, 4]. Conversely, triglyceride enrichment and/or a moderate decrease in the cholesteryl ester : triglyceride ratio has been observed in LDL in type 1 diabetic patients with good-tofair glycaemic control $[5,6]$.

In this paper we report on the first apolipoprotein (apo) B kinetic study of the VLDL $\rightarrow$ IDL $\rightarrow$ LDL cascade using endogenous stable isotope labelling. We studied type 1 diabetic patients with fair metabolic control under continuous subcutaneous insulin infusion administered by an external pump. The study was designed to evaluate whether abnormalities in the composition of apoB100-containing lipoproteins in type 1 diabetic subjects treated with sub- 
cutaneous insulin are associated with alterations in the kinetic parameters of these lipoproteins, in order to obtain further insight into the mechanisms underlying the increased risk of atherosclerosis in these patients.

\section{Subjects and methods}

\section{Subjects}

We studied eight men with type 1 diabetes and seven healthy men (control subjects). The type 1 diabetic subjects had been treated with subcutaneous insulin administered by an external pump (506 or 507 MiniMed pump; Medtronic MiniMed, Northridge, CA, USA) for at least 1 year (average $4.9 \pm 4.3$ years). They had no diabetic complications (microalbuminuria $<20 \mu \mathrm{g} / \mathrm{min}$ ) and were not taking any medication known to affect lipid metabolism. Control subjects were in good health, had normal fasting plasma glucose levels and were not taking any medication known to affect lipid metabolism. The study protocol was approved by the ethics committee at Dijon University Hospital and written informed consent was obtained from each subject.

\section{Experimental protocol}

The kinetic study was performed in the fed state. Patients were fed a leucine-poor diet $(1,700 \mathrm{kcal} / \mathrm{day} ; 55 \%$ carbohydrate, $39 \%$ fat and $7 \%$ protein) that was divided into small portions and given every $2 \mathrm{~h}$, starting at $6 \mathrm{~h}$ prior to the tracer infusion up to the end of the study. This was done to avoid important variations in apoB100 hepatic secretion, as reported previously by our group [7-9]. The endogenous labelling of apoB was carried out by the administration of L- $\left[1-{ }^{13}\right.$ C]leucine (99 atom\%; Eurisotop, Saint Aubin, France) dissolved in a $0.9 \% \mathrm{NaCl}$ solution. At 08.00 hours each subject received an intravenous primed infusion of $0.7 \mathrm{mg} / \mathrm{kg}$ of tracer, which was immediately followed by a $16-\mathrm{h}$ constant infusion of $0.7 \mathrm{mg} \cdot \mathrm{kg}^{-1} \cdot \mathrm{h}^{-1}$. Blood samples were drawn and collected in tubes containing a gel separator but no anticoagulant (Becton Dickinson, Meylan, France) at $0,0.5,1,1.5,2,3,4,6,8,10,12,14,15$ and $16 \mathrm{~h}$ after the primed infusion. Serum was separated by centrifugation for $10 \mathrm{~min}$ at $4{ }^{\circ} \mathrm{C}$ and $3,000 \times g$.

The type 1 diabetic patients received a bolus of insulin (4-6 U) at $08.00,12.00,18.00$ and 22.00 hours. The same total amount of insulin was administered in the boluses as usual, but it was fractionated into four instead of three boluses.

Analytical procedure

Isolation of apoB100 Gradient ultracentrifugation was used to isolate VLDL, IDL and LDL from plasma, using an SW41 rotor in an L90 ultracentrifuge (Beckman In- struments, Palo Alto, CA, USA). The VLDL fractions were then dialysed against $10 \mathrm{mmol} / \mathrm{l}$ ammonium bicarbonate buffer, $\mathrm{pH} 8.2$, containing $0.01 \%$ EDTA, $0.013 \%$ sodium azide. VLDL fractions were delipidated for $1 \mathrm{~h}$ at $-20^{\circ} \mathrm{C}$ using 10 volumes of diethylether-ethanol 3:1 (v/v). VLDL apoB was isolated by preparative SDS-PAGE. In brief, the delipidated apoB-containing material was solubilised in $0.05 \mathrm{~mol} / 1$ Tris buffer, $\mathrm{pH} 6.8$, containing 3\% SDS, 3\% mercaptoethanol, $10 \%$ glycerol, and applied to a $3-\mathrm{mm}$ thick vertical slab gel (3\% acrylamide). After staining with Coomassie Blue R-250, apoB100 was cut from the gel. IDL- and LDL-apoB were isolated by selective precipitation with butanol-isopropyl ether, as described previously [10]. ApoB100 was hydrolysed in $6 \mathrm{~N}$ $\mathrm{HCl}$ at $110^{\circ} \mathrm{C}$ for $16 \mathrm{~h}$. VLDL samples were then centrifuged to remove polyacrylamide. VLDL, IDL and LDL supernatants were lyophilised in a SpeedVac (Savant Instruments, Farmingdale, NY, USA). To totally remove the acrylamide, lyophilised samples of VLDL were dissolved in 50\% acetic acid, applied to an AG-50W-X8, 200-400 mesh cation exchange column (Bio-Rad, Richmond, CA, USA), and amino acids were recovered by elution with $4 \mathrm{~N} \mathrm{NH}_{4} \mathrm{OH}$ and then lyophilised.

Determination of leucine enrichment by gas chromatography/combustion/isotope ratio mass spectrometry Amino acids were converted into $N$-acetyl- $O$-propyl esters and then analysed on a Delta Plus Advantage isotope ratio mass spectrometer (Finnigan Mat, Bremen, Germany). Isotopic enrichment was initially expressed in delta (in units of \%o) and was converted into tracer : tracee ratios prior to modelling $[11,12]$.

Modelling Data were analysed with the Simulation Analysis and Modelling (SAAM) II program (SAAM Institute, Seattle, WA, USA) using the multicompartmental model shown in Fig. 1. A forcing function, corresponding to the plateau value for VLDL-apoB enrichment, was used to drive the appearance of leucine tracer into the different lipoprotein fractions $[8,9,13]$. The delay compartment represents the time required for the synthesis of apoB 100 and its secretion into the plasma. Compartments 3, 4 and 5 represent plasma VLDL-, IDL- and LDL-apoB100, respectively. A direct IDL- and LDL-apoB input was required to improve the fit to experimental data, as previously employed by other groups $[14,15]$.

As the experiment was conducted under steady-state conditions, the fractional synthetic rate was equal to the fractional catabolic rate (FCR). The direct FCR of VLDLapoB and the FCR from VLDL to IDL were equal to $k$ $(0,3)$ and $k(4,3)$, respectively. The total VLDL-apoB FCR was the sum of $k(0,3)$ and $k(4,3)$. The direct FCR of IDLapoB and the FCR from IDL to LDL were equal to $k(0,4)$ and $k(5,4)$, respectively. Total IDL-apoB FCR was the sum of $k(0,4)$ and $k(5,4)$. LDL-apoB FCR was $k(0,5)$.

The production rate of each lipoprotein fraction was calculated as the product of its total FCR and its pool size, divided by body weight. Pool size was calculated as the 


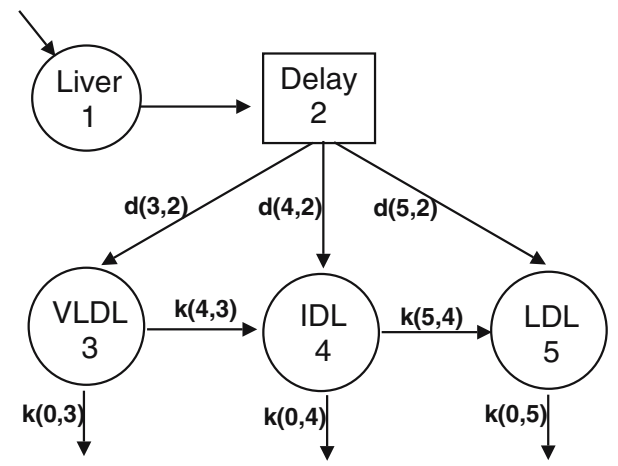

Fig 1 Multicompartmental model for the kinetic analysis of apoB100 metabolism. A forcing function, corresponding to the plateau value for VLDL apoB100 enrichment, was used to drive the appearance of leucine tracer into the different lipoprotein fractions (compartment 1). Compartment 2 is the delay compartment, representing the time required for the synthesis and secretion of apoB100 into the plasma. Compartments 3, 4 and 5 represent plasma VLDL-, IDL- and LDL-apoB100, respectively

product plasma volume and the apoB plasma concentration of the lipoprotein fraction. Plasma volume was estimated to be $4.5 \%$ of body weight $[9,15]$.

The pool sizes of VLDL-, IDL- and LDL-apoB were determined by calculating the mean apoB measurement of four taken at different times $(0,4,8$ and $12 \mathrm{~h}$ after the beginning of tracer infusion) and correcting this compared with plasma measurements. The same correction factor was applied to VLDL-, IDL- and LDL-apoB. The composition of the different lipoprotein fractions was calculated according to the same protocol.

\section{Laboratory measurements}

Plasma glucose concentrations were measured using an enzymatic method (glucose oxidase) on a Vitros 950 analyser (Ortho Clinical Diagnostics, Rochester, NY, USA). $\mathrm{HbA}_{1} \mathrm{c}$ was measured with ion exchange HPLC (Bio-Rad). Total and HDL cholesterol, triglyceride and apoB concentrations were measured on a Dimension analyser with dedicated reagents (Dade Behring, Newark, DE, USA). ApoB was measured by immunoturbidimetry; the intraassay CV was $<5 \%$ at $0.02 \mathrm{~g} / 1$. Free cholesterol was quantified on a Dimension analyser using reagents purchased from ImmunoChimie International (Bouffémont, France).
Esterified cholesterol was calculated as the difference between total and free cholesterol in each lipoprotein fraction.

Statistical analysis

Data are reported as means \pm SEM. Statistical calculations were performed using Statview software (SAS Institute, Cary, NC, USA). Quantitative data for the two groups of subjects were compared using the non-parametric MannWhitney $U$-test. A two-tailed $p$ value of 0.05 was considered statistically significant.

\section{Results}

Glucose metabolism parameters Clinical and glucose metabolism parameters are presented in Table 1. The type 1 diabetic patients had fair glycaemic control $\left(\mathrm{HbA}_{1} \mathrm{c}\right.$ $8.00 \pm 1.48 \%$ ) and had BMI values that were not statistically different from those for control subjects $(25.4 \pm 2.1$ vs $23.8 \pm 1.8 \mathrm{~kg} / \mathrm{m}^{2}$, respectively). Figure 2 shows the capillary glycaemia values in type 1 diabetic patients during the kinetic study, and indicates that glycaemic control was fair throughout the study. The mean glucose level during the day of the study was $8.33 \pm 2.00 \mathrm{mmol} / \mathrm{l}$.

Plasma lipid parameters Plasma lipid concentrations are presented in Table 1 . The type 1 diabetic patients and control subjects had similar triglyceride levels during the kinetic study. The total, LDL and HDL cholesterol levels for the two groups were also comparable.

The composition of the different apoB-containing lipoprotein fractions is detailed in Table 2. The VLDL particles in type 1 diabetic patients were $17 \%$ less triglyceride rich than those in control subjects $(p=0.05)$. We observed a trend towards an increase in the amount of cholesteryl esters in VLDL in type 1 diabetic patients compared with control subjects, but this difference did not reach statistical significance. Compared with the control group, the VLDL triglyceride : cholesteryl ester ratio was $35 \%$ lower in the type 1 diabetic group $(p=0.05)$. Levels of IDL triglycerides were $37 \%$ higher in the type 1 diabetic group than in the control group $(p<0.01)$. We also observed a trend towards an increase in cholesteryl esters in IDL in type 1 diabetic patients compared with control subjects, but this difference
Table 1 Clinical and biological characteristics of the study subjects

Values are means \pm SEM

\begin{tabular}{|c|c|c|}
\hline & Type 1 diabetic subjects $(n=8)$ & Control subjects $(n=7)$ \\
\hline Age (years) & $42 \pm 9.5$ & $35 \pm 7.2$ \\
\hline BMI $\left(\mathrm{kg} / \mathrm{m}^{2}\right)$ & $25.4 \pm 2.1$ & $23.8 \pm 1.8$ \\
\hline Fasting blood glucose $(\mathrm{mmol} / \mathrm{l})$ & - & $4.93 \pm 0.35$ \\
\hline $\mathrm{HbA}_{1} \mathrm{c}(\%)$ & $8.00 \pm 1.48$ & - \\
\hline Triglycerides (mmol/l) & $1.22 \pm 0.16$ & $1.10 \pm 0.34$ \\
\hline Total cholesterol (mmol/1) & $5.43 \pm 0.60$ & $4.75 \pm 0.54$ \\
\hline HDL cholesterol (mmol/l) & $1.40 \pm 0.15$ & $1.31 \pm 0.18$ \\
\hline LDL cholesterol (mmol/l) & $3.29 \pm 0.70$ & $3.01 \pm 0.65$ \\
\hline
\end{tabular}




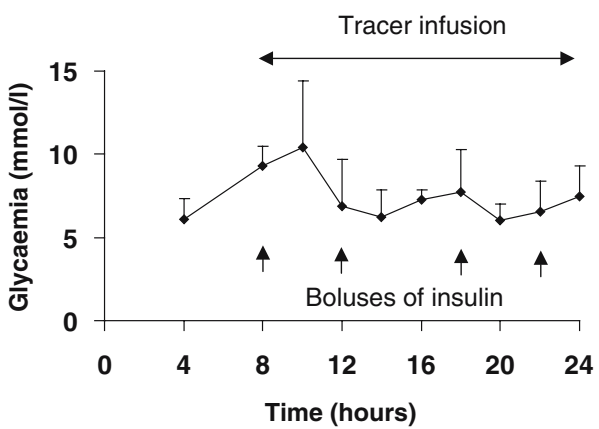

Fig 2 Glycaemic curve of the type 1 diabetic patients during the kinetic study. The data points show the means \pm SEM for capillary glycaemia in the eight type 1 diabetic patients participating in this study. The vertical arrows indicate the times at which the boluses of insulin (4-6 U) were administered

did not reach statistical significance $(p=0.08)$. The LDL triglyceride : apoB and triglyceride : cholesteryl ester ratios were 68 and $31 \%$ higher in type 1 diabetic patients than in control subjects, respectively.

Figure 3 shows the plasma triglyceride and VLDL-, IDL-, and LDL-apoB concentrations of one representative subject throughout the kinetic study. The CVs for these parameters were $14,15,9$ and 5\%, respectively.

Kinetic data The apoB kinetic parameters are shown in Table 3. The VLDL-, IDL- and LDL-apoB pools were not different between type 1 diabetic patients and control subjects in terms of the production rate and FCR for each lipoprotein subclass. For IDL and LDL, the proportion of particles directly synthesised by the liver was similar in type 1 diabetic patients and control subjects (data not shown).

Table 2 Composition of VLDL, IDL and LDL in the study subjects

Values are means \pm SE. ApoB concentrations are expressed in $\mathrm{g} / \mathrm{l}$ and lipid parameters are expressed in $\mathrm{mmol} / \mathrm{l}$

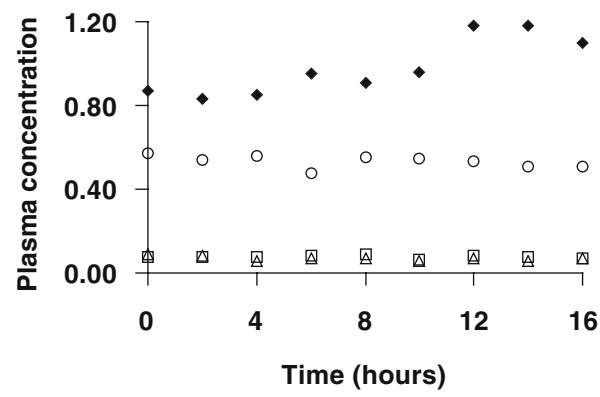

Fig 3 Plasma concentrations of triglycerides (diamonds), VLDLapoB (squares), IDL-apoB (triangles) and LDL-apoB (circles) in one representative diabetic subject during the kinetic study. Triglyceride concentrations are expressed in $\mathrm{mmol} / \mathrm{l}$ and apoB concentrations are expressed in $\mathrm{g} / \mathrm{l}$

\section{Discussion}

In this paper we report on the first stable isotope apoB kinetic study of the VLDL $\rightarrow$ IDL $\rightarrow$ LDL cascade in type 1 diabetic men treated with continuous subcutaneous insulin infusion. The apoB production rate and apoB FCR in our group of patients were similar to those in the control subjects for VLDL, IDL and LDL, despite significant differences in the composition of these lipoproteins.

We chose to study the metabolism of apoB in the postprandial state because this is the state most frequently experienced by humans over a $24-\mathrm{h}$ period. The daily food intake was divided into small portions, with one portion taken every $2 \mathrm{~h}$, starting at $6 \mathrm{~h}$ before the tracer perfusion in order to achieve a steady state of VLDL-, IDL- and LDLapoB concentrations throughout the kinetic study.

Type 1 diabetic subjects $(n=8) \quad$ Control subjects $(n=7) \quad p$ value

\begin{tabular}{lccc}
\hline VLDL & & & \\
Total cholesterol/apoB & $4.27 \pm 0.91$ & $3.64 \pm 0.82$ & 0.13 \\
Free cholesterol/apoB & $2.17 \pm 0.44$ & $2.03 \pm 0.54$ & 0.49 \\
Esterified cholesterol/apoB & $2.11 \pm 0.49$ & $1.61 \pm 0.29$ & 0.11 \\
Triglycerides/apoB & $6.91 \pm 0.81$ & $8.29 \pm 1.24$ & 0.05 \\
Phospholipids/apoB & $2.81 \pm 0.43$ & $2.94 \pm 0.61$ & 0.42 \\
Triglyceride/cholesteryl ester & $3.53 \pm 0.90$ & $5.43 \pm 1.19$ & 0.05 \\
IDL & & & \\
Total cholesterol/apoB & $5.13 \pm 0.84$ & $4.27 \pm 0.83$ & 0.11 \\
Free cholesterol/apoB & $1.70 \pm 0.25$ & $1.49 \pm 0.31$ & 0.20 \\
Esterified cholesterol/apoB & $3.43 \pm 0.61$ & $2.78 \pm 0.71$ & 0.08 \\
Triglycerides/apoB & $2.16 \pm 0.36$ & $1.57 \pm 0.30$ & 0.007 \\
Phospholipids/apoB & $2.32 \pm 0.31$ & $1.86 \pm 0.55$ & 0.12 \\
Triglycerides/cholesteryl ester & $0.64 \pm 0.06$ & $0.56 \pm 0.12$ & 0.27 \\
LDL & & & \\
Total cholesterol/apoB & $4.95 \pm 0.60$ & $4.60 \pm 0.48$ & 0.32 \\
Free cholesterol/apoB & $1.51 \pm 0.42$ & $1.35 \pm 0.24$ & 0.73 \\
Esterified cholesterol/apoB & $3.45 \pm 0.53$ & $3.25 \pm 0.52$ & 0.56 \\
Triglycerides/apoB & $0.27 \pm 0.06$ & $0.16 \pm 0.04$ & 0.01 \\
Phospholipids/apoB & $1.70 \pm 0.19$ & $1.52 \pm 0.15$ & 0.20 \\
Triglycerides/cholesteryl ester & $0.080 \pm 0.019$ & $0.061 \pm 0.025$ & 0.05 \\
\hline
\end{tabular}


Table 3 Kinetic parameters of VLDL-, IDL- and LDL-apoB100 in the study subjects

\begin{tabular}{|c|c|c|c|c|c|c|c|c|c|c|c|}
\hline & \multicolumn{4}{|c|}{ VLDL-apoB } & \multicolumn{4}{|l|}{ IDL-apoB } & \multicolumn{3}{|c|}{ LDL-apoB } \\
\hline & \multirow{2}{*}{$\begin{array}{l}\text { Pool } \\
(\mathrm{mg} / \mathrm{kg})\end{array}$} & \multirow{2}{*}{$\begin{array}{l}\text { Production } \\
\left(\mathrm{mg} \mathrm{kg}^{-1}\right. \\
\left.\text { day }^{-1}\right)\end{array}$} & \multicolumn{2}{|c|}{ FCR (pool/day) } & \multirow{2}{*}{$\begin{array}{l}\text { Pool } \\
(\mathrm{mg} / \mathrm{kg})\end{array}$} & \multirow{2}{*}{$\begin{array}{l}\text { Production } \\
\left(\mathrm{mg} \mathrm{kg}^{-1}\right. \\
\left.\text { day }^{-1}\right)\end{array}$} & \multicolumn{2}{|c|}{ FCR (pool/day) } & \multirow{2}{*}{$\begin{array}{l}\text { Pool } \\
(\mathrm{mg} / \mathrm{kg})\end{array}$} & \multirow{2}{*}{$\begin{array}{l}\text { Production } \\
\left(\mathrm{mg} \mathrm{kg}^{-1}\right. \\
\left.\text { day }^{-1}\right)\end{array}$} & \multirow{2}{*}{$\begin{array}{l}\text { FCR } \\
\text { (pool/day) }\end{array}$} \\
\hline & & & $\begin{array}{l}\text { Direct } \\
\text { catabolism }\end{array}$ & $\begin{array}{l}\text { Transfer } \\
\text { to IDL }\end{array}$ & & & $\begin{array}{l}\text { Direct } \\
\text { catabolism }\end{array}$ & $\begin{array}{l}\text { Transfer } \\
\text { to LDL }\end{array}$ & & & \\
\hline \multicolumn{12}{|c|}{ Type 1 diabetic subjects } \\
\hline 1 & 2.07 & 13.3 & 2.04 & 4.39 & 2.48 & 7.4 & 0 & 2.98 & 35.9 & 15.5 & 0.43 \\
\hline 2 & 2.03 & 19.8 & 2.54 & 7.25 & 5.45 & 17.5 & 0.79 & 2.42 & 27.2 & 15 & 0.55 \\
\hline 3 & 4.23 & 34.9 & 4.66 & 3.60 & 5.63 & 15.5 & 0 & 2.76 & 32.9 & 17.4 & 0.53 \\
\hline 4 & 2.79 & 24.4 & 4.01 & 4.75 & 3.92 & 15.0 & 0 & 3.84 & 22.1 & 17.0 & 0.77 \\
\hline 5 & 4.95 & 50.6 & 7.61 & 2.62 & 6.57 & 17.0 & 0 & 2.59 & 26.7 & 19.3 & 0.72 \\
\hline 6 & 4.14 & 34.4 & 0.07 & 8.23 & 5.09 & 34.2 & 3.29 & 3.43 & 39.2 & 17.9 & 0.46 \\
\hline 7 & 3.83 & 15.6 & 0.00 & 4.08 & 7.79 & 20.9 & 0.31 & 2.38 & 34.3 & 18.9 & 0.55 \\
\hline 8 & 4.68 & 31.0 & 4.82 & 1.80 & 2.57 & 9.4 & 0 & 3.67 & 20.2 & 11.2 & 0.55 \\
\hline Mean \pm SEM & $3.59 \pm 0.97$ & $28.0 \pm 9.72$ & $3.22 \pm 2.06$ & $4.58 \pm 1.62$ & $4.93 \pm 1.46$ & $17.0 \pm 5.3$ & $0.55 \pm 0.75$ & $3.00 \pm 0.48$ & $29.8 \pm 5.6$ & $16.6 \pm 1.96$ & $0.57 \pm 0.09$ \\
\hline Median & 3.98 & 27.7 & 3.28 & 4.24 & 5.27 & 16.3 & 0.00 & 2.87 & 30.0 & 17.2 & 0.55 \\
\hline \multicolumn{12}{|c|}{ Control subjects } \\
\hline 1 & 1.80 & 23.1 & 1.37 & 11.45 & 5.18 & 29.7 & 3.48 & 2.26 & 23.2 & 18.9 & 0.82 \\
\hline 2 & 3.11 & 19.9 & 1.61 & 4.80 & 4.59 & 18.2 & 0 & 3.96 & 33.8 & 26.0 & 0.77 \\
\hline 3 & 1.08 & 12.1 & 4.27 & 6.94 & 4.41 & 11.0 & 0 & 2.50 & 42.8 & 15.4 & 0.36 \\
\hline 4 & 5.27 & 22.5 & 0 & 4.27 & 4.50 & 23.5 & 2.42 & 2.81 & 42.0 & 16.1 & 0.38 \\
\hline 5 & 4.50 & 42.6 & 4.70 & 4.75 & 3.83 & 21.4 & 1.54 & 4.06 & 32.2 & 17.0 & 0.53 \\
\hline 6 & 2.30 & 28.4 & 5.98 & 6.41 & 2.43 & 15.7 & 0.6 & 5.86 & 27.7 & 16.6 & 0.60 \\
\hline 7 & 8.78 & 49.1 & 3.82 & 1.78 & 7.52 & 16.6 & 0 & 2.21 & 21.5 & 16.5 & 0.77 \\
\hline Mean \pm SEM & $3.83 \pm 2.01$ & $28.3 \pm 10.1$ & $3.10 \pm 1.81$ & $5.76 \pm 2.14$ & $4.64 \pm 0.98$ & $19.4 \pm 4.6$ & $1.15 \pm 1.14$ & $3.38 \pm 1.07$ & $31.9 \pm 6.7$ & $18.0 \pm 2.5$ & $0.60 \pm 0.15$ \\
\hline Median & 3.11 & 23.1 & 3.82 & 4.80 & 4.50 & 18.2 & 0.60 & 2.81 & 32.2 & 16.6 & 0.50 \\
\hline$p$ value & 0.91 & 0.86 & 0.86 & 0.39 & 0.49 & 0.33 & 0.39 & 0.82 & 0.64 & 0.91 & 0.69 \\
\hline
\end{tabular}

The abnormalities in apoB-containing lipoprotein composition in our type 1 diabetic men are similar to those previously reported by others in patients with good-to-fair glycaemic control.

In our patients, VLDL particles were poor in triglycerides and rich in cholesteryl esters, though the change in the amount of the latter was not statistically significant. These results are consistent with previous studies $[3,4]$. Insulin controls hepatic VLDL secretion via different mechanisms by decreasing the delivery of NEFA by adipose tissue, a substrate for hepatic triglyceride synthesis, and inhibiting the synthesis and secretion of VLDL particles by the liver. VLDL particles are assembled in hepatocytes in two steps. Initially, an apoB100-containing precursor, poor in triglycerides, is formed in the endoplasmic reticulum; this subsequently merges with a large droplet of triglyceride to form a triglyceride-rich, mature VLDL. Microsomal triglyceride transfer protein (MTP) facilitates the transfer of lipid, particularly triglycerides, throughout the membranes and is required for the two VLDL assembly steps. Insulin controls VLDL-apoB production by inhibiting MTP activity and by directing intracellular triglyceride into the intracytoplasmic storage compartment instead of into newly synthesised VLDL [16-18].

Consistent with previous results [19], the type 1 diabetic men and healthy control subjects in our study had similar VLDL-apoB production rates. This finding indicates that, in our type 1 diabetic subjects, portal insulinisation was sufficient to maintain a normal apoB production rate, despite the peripheral subcutaneous administration of insulin. In a previous study, type 1 diabetic patients with good glycaemic control under continuous subcutaneous insulin infusion were shown to have a reduced hepatic production rate of VLDL triglycerides compared with healthy subjects [4]. Taken together, these results suggest the coexistence of a decreased VLDL triglyceride production rate and a normal VLDL-apoB production rate in type 1 diabetic patients with good-to-fair glycaemic control under subcutaneous insulin infusion, which could explain the lower levels of VLDL triglycerides usually observed in these patients. This hypothesis is supported by the results of in vitro studies demonstrating that hepatocytes are able to secrete apoB-containing lipoproteins with variable triglyceride contents, depending on the intracellular availability of triglycerides [16]. Moreover, in humans, we know from simultaneous kinetic studies of VLDL triglycerides and apoB100 that variations in VLDL triglycerides and apoB production rates are not directly related $[20,21]$. The reasons for the decreased production rate of VLDL triglycerides in type 1 diabetic patients treated with subcutaneous insulin are not fully understood. A simultaneous kinetic study of VLDL triglycerides and plasma NEFA is necessary to better understand the relationships between these two parameters in type 1 diabetic patients. 
Alternatively, a low VLDL triglycerides : apoB ratio could be attributable to increased lipoprotein lipase (LPL) activity. However, in several studies, type 1 diabetic patients and control subjects have been shown to have similar levels of LPL activity [22-24]. Moreover, if LPL activity were increased in type 1 diabetes mellitus, VLDL catabolism would be expected to be accelerated; however, this was not observed in the present study.

Triglyceride enrichment of LDL, another characteristic abnormality of lipoprotein composition in type 1 diabetes mellitus, was also observed in this study. This observation has previously been explained by a decrease in hepatic lipase activity in type 1 diabetic subjects treated with subcutaneous insulin. In these patients, hepatic lipase activity has been demonstrated to be inversely correlated with the LDL triglycerides : cholesterol ratio [23, 25]. The relative increase in the amount of LDL triglycerides could also be explained by the increased cholesteryl ester transfer protein activity demonstrated in these patients, especially if hepatic lipase activity is low $[22,26]$. This reasoning is consistent with the observed trend towards cholesteryl ester enrichment of VLDL in our study. The triglyceride enrichment of LDL particles modulates the conformation of apoB, which, in turn, decreases the affinity of these particles for their receptor in vitro $[27,28]$. Thus, one of the major aims of our work was to determine whether LDL triglyceride enrichment was associated with decreased LDL catabolism in type 1 diabetic patients. Our results did not indicate any modification of the FCR for LDL. In the previously mentioned studies demonstrating changes in the conformation of the apoB binding site to the LDL receptor at the surface of triglyceride-enriched LDL or a decreased affinity of these particles for their receptor, the LDL particles contained 2.5-3 times more triglycerides than the control LDL particles. In our type 1 diabetic patients, LDL triglyceride enrichment was less than twofold greater than in control subjects, which could explain why we did not observe any decrease in the LDL FCR. The triglyceride enrichment of LDL in type 1 diabetic patients is usually not as high as that observed in in vitro studies, but is similar to that observed in our in vivo study (less than twofold) $[5,6]$. Thus, the LDL triglyceride enrichment observed in vivo in type 1 diabetes is not likely to modify LDL catabolism. The glycation of apoB100 is another abnormality that could decrease the affinity of LDL particles for their receptor in type 1 diabetic patients. Although we did not assess LDL glycation in the subjects participating in our study, it has previously been shown that, in diabetic patients with a good-to-fair glycaemic control, the difference in LDL glycation between patients and healthy subjects was small and we think that it is probably not sufficient to impair the LDL FCR [29].

In conclusion, in type 1 diabetic men with fair glycaemic control under continuous subcutaneous insulin infusion administered by an external pump, the values of apoB 100 kinetic parameters for all apoB100-containing lipoproteins are comparable to those observed in healthy control subjects. In these patients, VLDL with a poor triglyceride content is associated with a normal VLDL-apoB synthesis rate and FCR. Conversely, the triglyceride enrichment of LDL does not induce changes in the FCR for LDL-apoB. Thus, the increased cardiovascular risk in type 1 diabetic patients with fair glycaemic control cannot be related to quantitative or kinetic differences in apoB100-containing lipoproteins. The mechanisms underlying the development of atherosclerotic lesions in type 1 diabetes differ in some respects from those observed in type 2 diabetes. Indeed, type 2 diabetes, which is characterised by obesity and insulin resistance, is associated with a decreased LDL turnover rate and increased concentrations of VLDL and IDL particles, which are the result of increased production rates and decreased FCRs [8].

Acknowledgements This investigation was supported by the University of Burgundy, the Regional Council of Burgundy (Conseil régional de Bourgogne), and the National Institute of Health and Medical Research (Institut National de la Santé et de la Recherche Médicale, INSERM). We are indebted to V. Jost for the preparation of the ${ }^{13} \mathrm{C}$-leucine, C. Gibassier for dietary assistance, and D. Battaut, E. Niot and L. Princep for invaluable technical assistance. The authors are not aware of any duality of interest.

\section{References}

1. Lopes-Virella MF, Wohltmann HJ, Loadholt CB, Buse MG (1981) Plasma lipids and lipoproteins in young insulin-dependent diabetic patients: relationship with control. Diabetologia 21:216-223

2. Perez A, Wagner AM, Carreras G et al (2000) Prevalence and phenotypic distribution of dyslipidemia in type 1 diabetes mellitus: effect of glycemic control. Arch Intern Med 160:27562762

3. Rivellesse A, Riccardi G, Romano G et al (1988) Presence of very low density lipoprotein compositional abnormalities in type 1 diabetic patients; effect of blood glucose optimization. Diabetologia 31:884-888

4. Pietri AO, Dunn FL, Raskin P (1983) The effect of continuous subcutaneous insulin infusion on very low density lipoprotein triglyceride metabolism in type 1 diabetes mellitus. Diabetes 32:75-81

5. Winocour PH, Durrington PN, Bhatnagar D, Ishola M, Arrol S, Mackness M (1992) Abnormalities of VLDL, IDL and LDL characterize insulin-dependent diabetes mellitus. Arterioscler Thromb 12:920-928

6. James RW, Pometta D (1990) Differences in lipoprotein subfraction composition and distribution between type 1 diabetic men and control subjects. Diabetes 39:1158-1164

7. Duvillard L, Pont F, Florentin E, Gambert P, Vergès B (2000) Significant improvement of apoB-containing lipoprotein metabolism by insulin treatment in NIDDM patients. Diabetologia 43:27-35

8. Duvillard L, Pont F, Florentin E, Gambert P, Vergès B (2000) Atherogenic abnormalities of apolipoprotein B-containing lipoprotein metabolism in NIDDM demonstrated by a stable isotope kinetic study. Eur J Clin Investig 30:685-694

9. Pont F, Duvillard L, Florentin E, Gambert P, Vergès B (2002) Early kinetic abnormalities of apoB-containing lipoproteins in insulin-resistant women with abdominal obesity. Arterioscler Thromb Vasc Biol 22:1726-1732

10. Klein RL, Zilversmit DB (1984) Direct determination of human and rabbit apolipoprotein B selectively precipitated with butanol-isopropyl ether. J Lipid Res 25:1380-1386

11. Cobelli C, Toffolo G, Foster DM (1992) Tracer-to-tracee ratio for analysis of stable isotope tracer data: link with radioactive formalism. Am J Physiol 262:E968-E975 
12. Pont F, Duvillard L, Vergès B, Gambert P (1998) Development of compartmental models in stable isotope experiments: application to lipoprotein metabolism. Arterioscler Thromb Vasc Biol 18:853-860

13. Millar JS, Lichtenstein AH, Cuchel M et al (1995) Impact of age on the metabolism of VLDL, IDL, and LDL apolipoprotein B100 in men. J Lipid Res 36:1155-1167

14. Demant T, Packard CJ, Demmelmair H (1996) Sensitive methods to study human apolipoprotein B metabolism using stable isotope-labeled amino-acids. Am J Physiol 270:E1022-E1036

15. Ouguerram K, Chetiveaux M, Zair Y et al (2004) Apolipoprotein B metabolism in autosomal-dominant hypercholesterolemia related to mutations in PCSK9. Arterioscler Thromb Vasc Biol 24:1-6

16. Gibbons GF, Wiggings D, Brown AM, Hebbachi AM (2004) Synthesis and function of hepatic very-low-density lipoprotein. Biochem Soc Trans 32:59-64

17. Dixon JL, Ginsberg HN (1993) Regulation of apolipoprotein Bcontaining lipoproteins: information obtained from cultured cell liver. J Lipid Res 34:167-179

18. Brown AM, Gibbons GF (2001) Insulin inhibits the maturation phase of VLDL assembly via a phosphoinositide 3-kinasemediated event. Arterioscler Thromb Vasc Biol 21:1656-1661

19. Christ ER, Carroll PV, Albany E et al (2001) Normal VLDL metabolism despite altered lipoprotein composition in type 1 diabetes mellitus. Clin Endocrinol (Oxf) 55:777-787

20. Lewis GF, Uffelman KD, Szeto LW, Weller B, Steiner G (1995) Interaction between free fatty acids and insulin in the acute control of very low density lipoprotein production in humans. $\mathrm{J}$ Clin Invest 95:158-166

21. Lewis GF, Uffelman KD, Szeto LW, Steiner G (1993) Effects of acute hyperinsulinemia on VLDL triglyceride and VLDL apoB production in normal weight and obese individuals. Diabetes 42:833-842
22. Bagdade JD, Dunn FL, Eckel RH, Ritter MC (1994) Intraperitoneal insulin therapy corrects abnormalities in cholesteryl ester transfer and lipoprotein lipase activities in insulin-dependent diabetes mellitus. Arterioscler Thromb 14:1933-1939

23. Caixas A, Perez A, Payes A et al (1998) Effects of a short acting insulin analog (Insulin Lispro) versus regular insulin on lipid metabolism in insulin-dependent diabetes mellitus. Metabolism 47:371-376

24. Ruotolo G, Parlavecchia M, Taskinen MR et al (1994) Normalization of lipoprotein composition by intraperitoneal insulin in IDDM. Role of increased hepatic lipase activity. Diabetes Care 17:6-12

25. Rosental SB, Schreier LE, Halperin H et al (1995) Low density lipoprotein rich in triglycerides and hepatic lipase activity in insulin-dependent diabetic patients [article in Spanish]. Medicina (B Aires) 55:317-323

26. Ritter MC, Bagdade JD (1994) Contribution of glycaemic control, endogenous lipoproteins and cholesteryl ester transfer protein to accelerated cholesteryl transfer in IDDM. Eur J Clin Invest 24:607-614

27. Viens L, Lagrost L (1997) Effect of lipid transfer activity and triglyceride hydrolysis on apolipoprotein B immunoreactivity in modified low density lipoproteins. J Lipid Res 38:1129-1138

28. Aviram M, Lund-Katz S, Phillips MC, Chait A (1988) The influence of the triglyceride content of low density lipoprotein on the interaction of apolipoprotein B-100 with cells. J Biol Chem 263:16842-16848

29. Panteghini M, Cimino A, Pagani F, Girelli A (1995) Nonenzymatic glycation of apolipoprotein $\mathrm{B}$ in patients with insulinand noninsulin-dependent diabetes mellitus. Clin Biochem 28:587-592 